\title{
2.4 GHZ SQUARE RING PATCH WITH RING SLOT ANTENNA FOR SELF INJECTION LOCKED RADAR
}

\author{
Irfan Mujahidin, Basitha Febrinda Hidayatulail, Putri Surya Arinda
}

\begin{abstract}
The radar network system requires high-cost frequency, the complex configuration component of the electromagnetic feeding network circuit to make four output antenna with the same power and different phase output specifically for SIL (Self Injection Locked) Radar, and inexpensive material, especially for the electromagnetic component. 2.4 GHz Square Ring Patch with Ring Slot Microstrip Antenna with four output that has the same power using power divider and 90-degree phase different output for SIL Radar. this is the novel shaped microstrip Antenna with the free frequency, more unassuming configuration, and inexpensive material at the $2.4 \mathrm{GHz}$ for SIL Radar. This system is an important part component of SIL Radar that is package consists of a $2.4 \mathrm{GHz}$ Microstrip antenna with the Square Ring Patch with Ring Slot, double power divider which is double input with quad output with the same power and directional coupler 90-degree phase difference with two input and two output. The Antenna has single band and narrow bandwidth with the frequency is $2.38 \mathrm{GHz}$ until $2.43 \mathrm{GHz}$ under $-10 \mathrm{~dB} \mathrm{~S}$ parameter and frequency resonance $2.4 \mathrm{GHz}$, the radiation pattern is directional and the gain is $8.37 \mathrm{dBi}$, The Power divider has $S$ parameter 2 port output of one part under $-20 \mathrm{~dB}$ at 2.4 $\mathbf{G H z}$ and isolation above $-4 \mathrm{~dB}$ that is all good agreement.

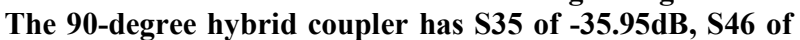
35.09 , S53 of -3.47 , and S64 of -3.39 that all is qualified good operation. And size all of the indicate antenna systems is 100 $\mathrm{mm}$ and $55.7 \mathrm{~mm}$ with Phenolic White Paper with a constant dielectric is 4.4 that has 50 ohms.
\end{abstract}

Index Terms - Microstrip antenna,SIL Radar, Square Ring patch.

\section{INTRODUCTION}

$\mathrm{M}$ ost develop technology right now is telecommunications structure especially radar as a wireless sensor, there has been an exceptional intensify in the interest of antennas circuit due to the expansion of wireless sensor and telecommunication technologies. sundry antenna, double divider and phase differentiator

Irfan Mujahidin is a lecturer in the Electrical Engineering Universitiy Merdeka Malang, Malang, Indonesia (Email : irfan.mujahidin@unmer.ac.id)

Basitha Febrinda Hidayatulail is a lecturer in the Electrical Engineering Universitiy Merdeka Malang, Malang, Indonesia (Email : basitha@unmer.ac.id).

Putri Surya Arinda is a Department of Phiysics student, University Brawijaya, Malang, Indonesia (Email : putrisuryaarinda@gmail.com). designs for SIL radar technology have been indicate[1][2][3][4]. Wireless sensor and navigation configuration system require a compact, not complex, low cost and efficient antenna. Some Experiment, we use large size antennas and use not simple of electromagnetic circuits in the process of phase comparison with 90degree difference angles on the navigation system. This requires high-cost material because every upperfrequency antenna needs the substance with the lowest disadvantage. In adjunct, fuse the antenna has a consistency in complex implemented to produce 90 degrees phase distinction and other two output with the same power for SIL radar system so need a lot of electromagnetic circuits that high cost[5].

The manner using sundry tier strip of electromagnetic circuits more effective than common electric circuit due to it bring down the costs power to transform energy out of the antenna to the next favorable component[6]. Moreover, to show and hard-headed, this structure is very convenient to replicate, implemented and can be good utilized. With a compact size and has, an upperfrequency antenna is also adequate to generate the high gain. The SIL radar composition system can be catch upon in figure 1 :

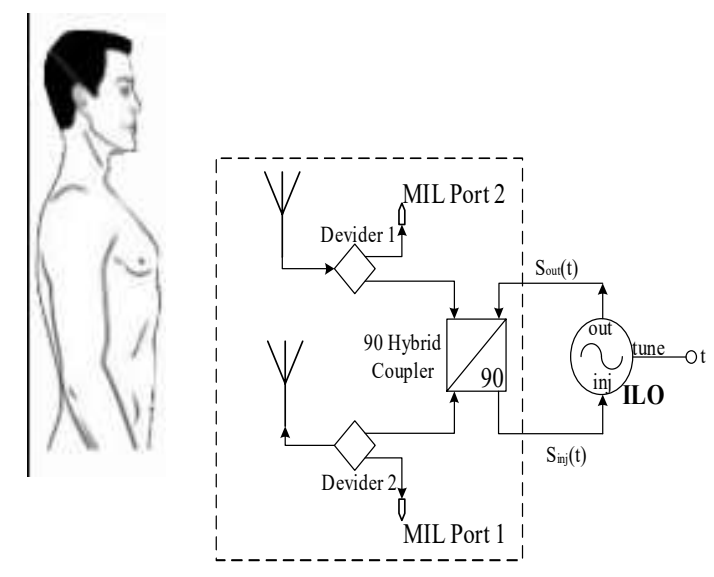

Figure. 1. Self Injection Locked Radar configuration 
In this research, a small size antenna suddenly stand up of a $2.4 \mathrm{GHz}$ Square Ring Patch with Ring Slot antenna with two power divider additional 90-degree hybrid coupler to produce 90 degree phase difference output as feeding network of SIL radar, the twofold antenna has been generating to obtain adequate to deliver a high gain for mobile and communication applications conjoined with phase difference coupler[7][8][9][10]. This delve generate a not complex and efficient method for crafty novel shaped antenna with a feeding connection network for SIL radar without complicated circuit design, implementing process and using cheap materials at elevated frequency.

\section{RESEARCH METHOD}

In this research, it is mainly to the design and implementation of a Square Ring Patch with Ring Slot antenna that is integrated with the feeding network consist double power divider and 90-degree hybrid coupler are used for SIL radar. in figure 2 is shown the dimension of the proposed miniaturized $2.4 \mathrm{GHz}$ square frame patch Antenna Square Ring Patch with Ring Slot antenna[11]. In this Figure 2, bending two transmission lines $\lambda / 4$ connected to Square Ring Patch with Ring Slot antenna respectively have been constructed using the PCB Laminate substrate with a of $0.8 \mathrm{~mm}$ and the copper with the thickness of $0.035 \mathrm{~mm}$
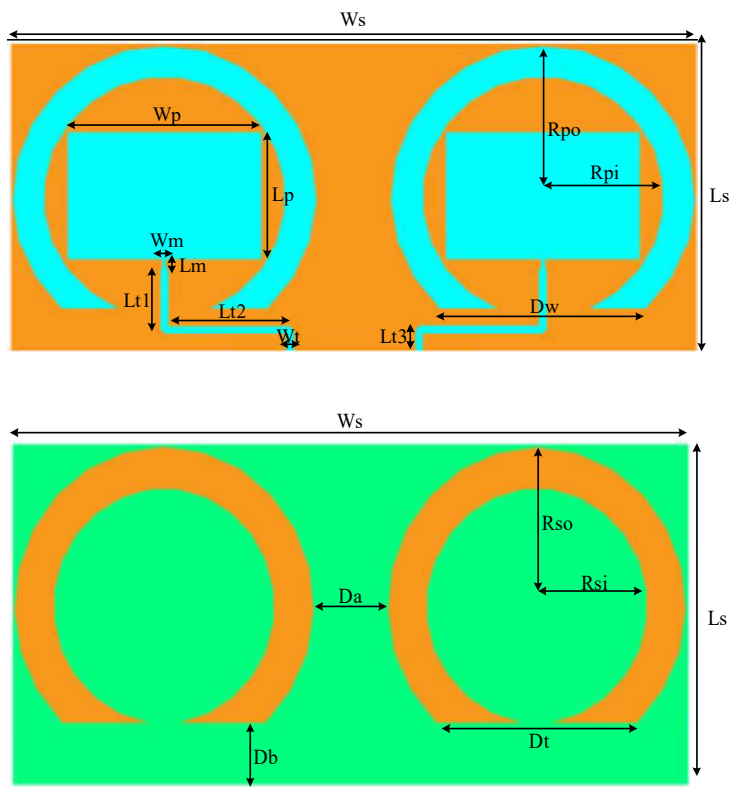

Figure. 2. Structure Square Ring Patch with Ring Slot antenna, (a) Front, and (b) Rear

Tabel 1. Dimension Of Antenna

\begin{tabular}{cc}
\hline \hline Variable & $\begin{array}{c}\text { Dimension } \\
(\mathrm{mm})\end{array}$ \\
Ws & 158.2 \\
Ls & 61.2 \\
Wp & 44.7 \\
Lp & 29.25 \\
Rpo & 27.79
\end{tabular}

\begin{tabular}{cc}
\hline \hline Variable & $\begin{array}{c}\text { Dimension } \\
(\text { mm) }\end{array}$ \\
Rpi & 34.72 \\
Wm & 0.73 \\
Lm & 2.4 \\
Lt1 & 13.25 \\
Lt2 & 28.10 \\
Lt3 & 7.76 \\
Wt & 1.5 \\
Dw & 47.93 \\
Rso & 34.98 \\
Rsi & 25.98 \\
Da & 17.52 \\
Dt & 48.23 \\
Db & 13.55 \\
Rpo & 27.79 \\
Rpi & 34.72 \\
Wm & 0.73 \\
Lm & 2.4 \\
Lt1 & 13.25 \\
Lt2 & 28.10 \\
Lt3 & 7.76 \\
Wt & 1.5 \\
Dw & 47.93 \\
Rso & 34.98 \\
Rsi & 25.98 \\
Da & 17.52 \\
Dt & 48.23 \\
Db & 13.55 \\
\hline \hline Db & 13.55 \\
\hline \hline
\end{tabular}

Basically, This configuration has two antenna each has one patch square shaped as radiating element with ring patch and ring slot on the rear substrate in order to focus the patch radiating to direct the front of the antenna which is the radiating element geometry can be generated through the formula :

$$
L p=\frac{1}{2 f_{r} \sqrt{\epsilon_{r e f f}} \sqrt{\mu_{0} \epsilon_{0}}}-2 \Delta L
$$

Where Lp is the patch length and fr is the resonant frequency The $2.4 \mathrm{GHz}$ Square Ring Patch with Ring Slot antenna design is finished by mathematics on the matter and matrix delivers from the literature[12][13]. The product of the concept then simulated using the scheming software to specify the parameters of the Square Ring Patch with Ring Slot antenna. 90-degree hybrid coupler design, power divider design, and antenna simulation are important to indicate the delimitation of the scheming whether it is corresponding or not as hoped-for of the performance.

In Figure 3., the electromagnetic scheming of the suggest miniaturized $2.4 \mathrm{GHz}$ feeding network for SIL Radar. In Figure 3, the main transmission line quarter $\lambda$ has been implemented using a PCB double-layer substrate with a thickness of $0.8 \mathrm{~mm}$ on the feeding network. These have six-port, double-port as power adopted from the antenna, and 4 port as outcome double output as power divider with the same power output and two output has 90-degree phase difference output[14] 


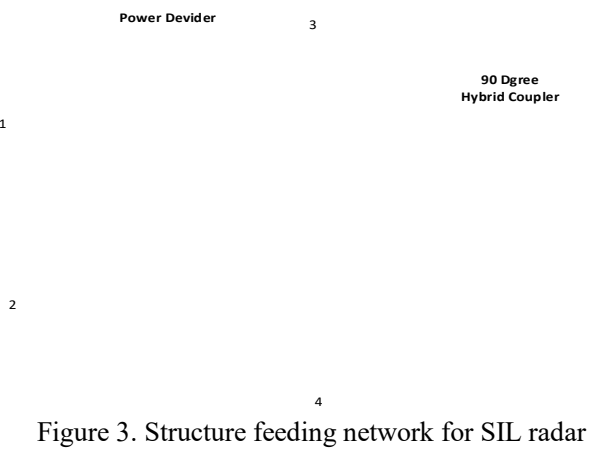

The operation of the feeding network is as attend: With 6 ports balanced, power influx from the antenna to port 2 and 1 is evenly divisible among to ports 4 and 4 as output and other output of power divider as input of 90 degrees directional coupler, with the same frequency and same power among these outputs at $2.4 \mathrm{GHz}$ working frequency. No signal is coupled 3 to 1,4 to 2 , directional coupler to 1 , and directional coupler to 2 these are isolated[15][16][17]. The power divider can be modeled with a double stepped power divider multisection. port 5 and port 6 as the output of 90 -degree hybrid coupler to produce 90 degree phase difference output. No power is coupled 5 to the power divider, 6 to the power divider these are isolated.

The Two $2.4 \mathrm{GHz}$ antenna specifications as input, the 3 step multi section power divider, the maximum $\mathrm{s}$ parameter $-15 \mathrm{~dB}$, and the equal split $3 \mathrm{~dB}$ then obtained impedance matching value with chebyshev response is $\mathrm{Z} 01=91.64 \Omega, \mathrm{Z} 02=70.65 \Omega$, and $\mathrm{Z} 03=54.58 \Omega$ and with the expected isolation analysis is above $-4 \mathrm{~dB}$, the resistance value can be determine $\mathrm{R} 1=151 \Omega, \mathrm{R} 2=470$ $\Omega$, and R3 = $822 \Omega[18]$.

\section{RESULT AND ANALYSIS}

Figure 4. shows the prototype of the Square Ring Patch with Ring Slot Antenna microstrip antenna for SIL Radar that has been manufactured. The ring patch on antenna faces is used to establish directional radiation to the front, high gain and optimum efficiency with not big and tight antenna dimension [13]. The overall Ring Patch with Ring Slot Antenna microstrip antenna size of the proposed antenna is $55.7 \mathrm{~mm} \times 49.2 \mathrm{~mm}$

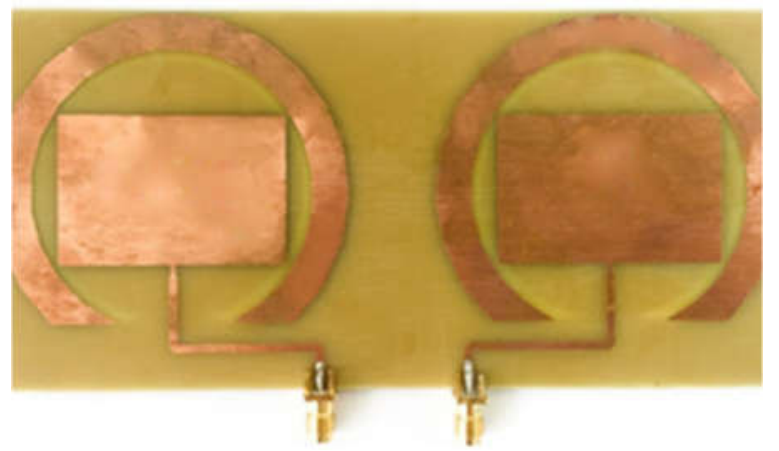

Figure 4. Physical prototype of square Square Ring Patch with Ring Slot antenna

To define the antenna resonance as the frequency band of the Double Square Margin antenna, in Figure 5, it shows the s parameter value of the microstrip Double
Square Margin antenna parameter as an antenna specification.

To assign the resonance as the frequency band of the Square Ring Patch with Ring Slot patch microstrip antenna, in Figure 5, it shows the s parameter value of the microstrip Square Ring Patch with Ring Slot antenna parameter as a reference.

S parameter of the Square Ring Patch with Ring Slot microstrip antenna has good congruence $\mathrm{S}$ parameter values that are $18.54 \mathrm{~dB}$ on $2.4 \mathrm{GHz}$ and have bandwidth $50 \mathrm{MHz}$ in under $-10 \mathrm{~dB}$. with a narrow band, it can increase the effectiveness of electric circuits to not using the complex bandpass filters.

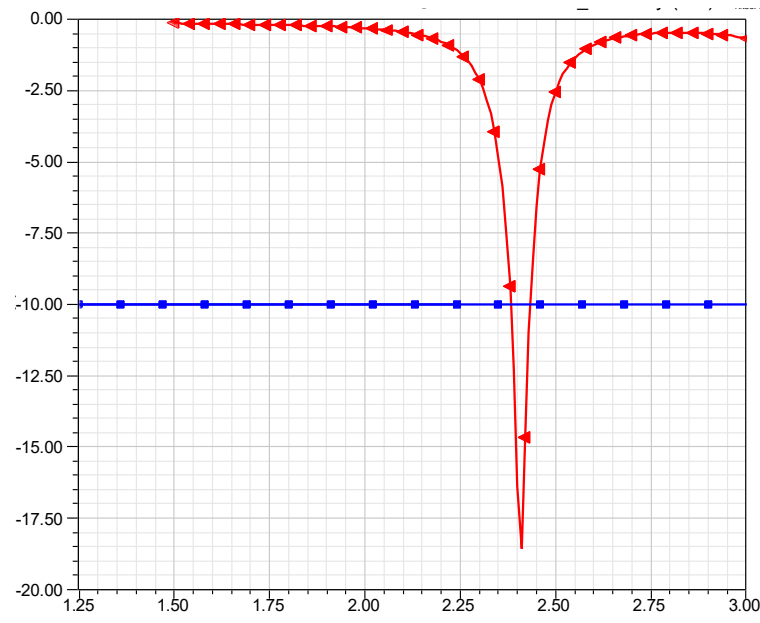

Figure 5. S parameter of square Square Ring Patch microstrip

To delineate the graphics possession of far-field pattern Square Ring Patch with Ring Slot microstrip antenna radiation pattern from as a purpose of sphere ball coordinates [14]. It is necessary to describe the far-field pattern of the microstrip antenna. The following Figure 6. is the Square Ring Patch with Ring Slot microstrip antenna radiation pattern:

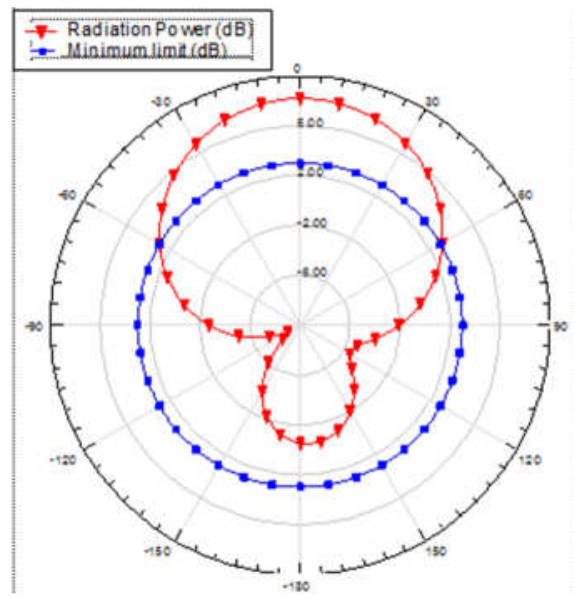

Figure 6. (a) Theta angles of The far-field pattern 


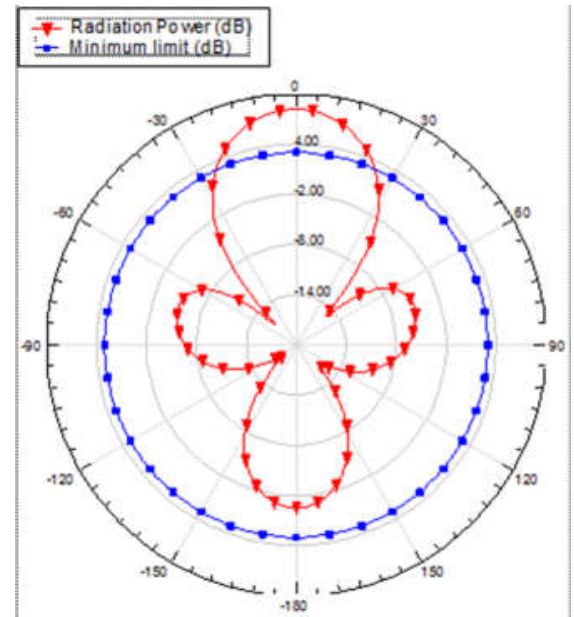

(b)

Figure 6. (b) Phi angles of The far-field pattern of the Square Ring Patch with Ring Slot antenna

The radiation pattern has a good congruence level of the configuration and the level. through the design of the far-field radiation has a focus main lobe of the biggest and has minor side lobe and back lobe, it can be deduced that the Square Ring Patch with Ring Slot antenna farfield radiation is directional far-field radiation. To represent the potency of power in a specific direction to the strengthening of the Square Ring Patch with Ring Slot antenna reference power according to need to describe antenna gain power [15]. Following the gain power :

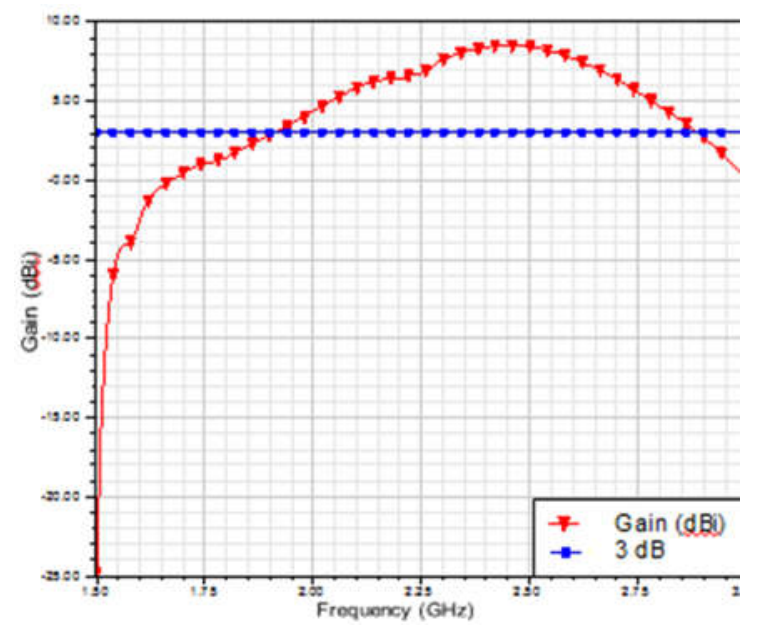

Figure 7. The Gain of Square Ring Patch with Ring Slot microstrip antenna

Figure 7. demonstrated the increased level of the microstrip radio wire has the estimation of $8.37 \mathrm{dBi}$. this demonstrates high reception apparatus gain for microstrip receiving wire with the recurrence of $2.4 \mathrm{GHz}$ for a twofold fix and twofold opening so it makes an exhibit radio wire to build the increased control. The twofold control divider for Square Ring Patch with Ring Space $2.4 \mathrm{GHz}$ reception apparatus is produced utilizing a similar material as the receiving wires Phenolic White Paper with a minimal effort and simple to discover. On Figure. 8 demonstrated the physical structure of the fabricated power divider incorporated with a 90-degree mixture coupler for square Ring Patch with Ring Opening patch $2.4 \mathrm{GHz}$.

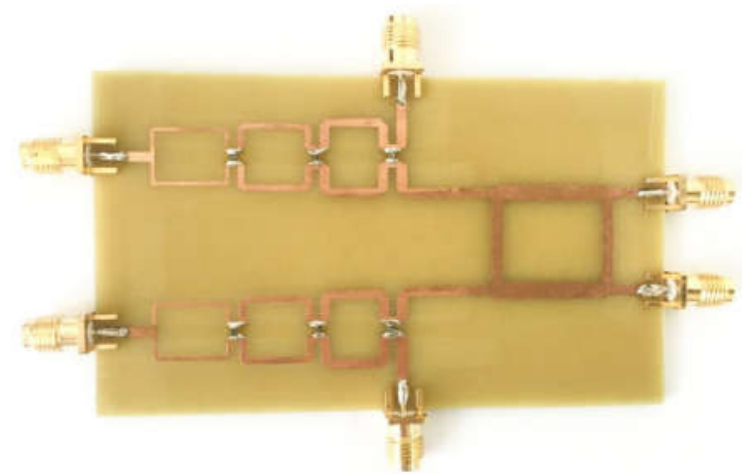

Fig 8. Implemented of integrated $2.4 \mathrm{GHz}$ power divider with 90 degree hybrid coupler for the square Ring Patch with Ring Slot antenna directional coupler

On the Figure. 9 demonstrates the S-parameter estimations of each yield port power divider. $2.4 \mathrm{GHz}$ control divider demonstrated square Ring Patch with Ring Space fix radio wire utilizes one line in and two lines out of once control divider with 50-ohm impedance each line. 2.4 GHz control divider has a high level of balance as to separate the power coupler, as two-port can be utilized as the contribution from the radio wire and two yield port to MIL port [18]. The estimation of S parameter of each port yield at $2.4 \mathrm{GHz}$ recurrence thunderous band can be pursued: S13 has an estimation of $-25.83 \mathrm{~dB}$ and $\mathrm{S} 24$ has an estimation of - $28.20 \mathrm{~dB}$.

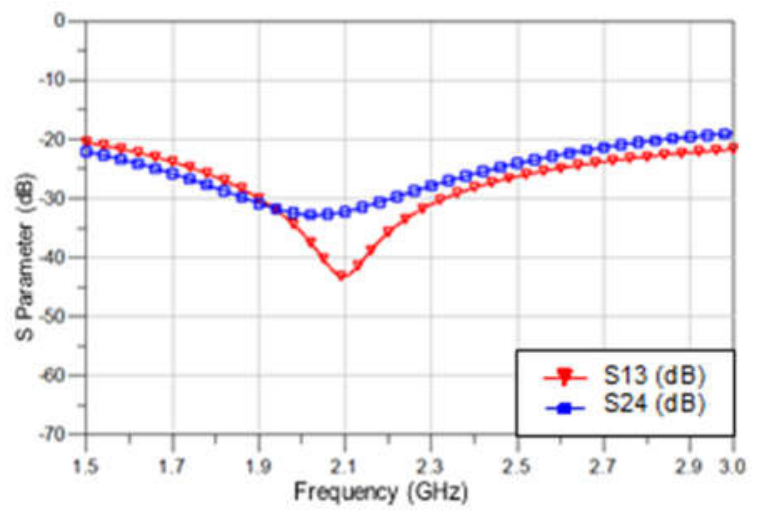

Figure 9. S parameter of the power divider

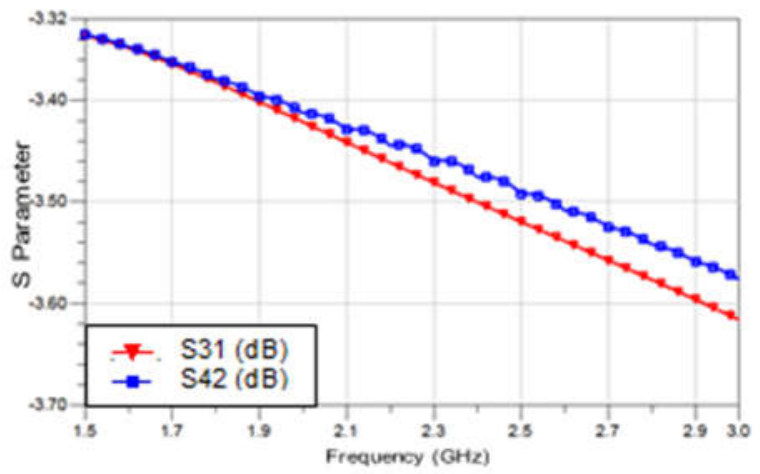

Figure 10. Isolation of the power divider 
On figure 10 decide The confinement. The disconnection is shown in s parameters S31 and S42 with the accompanying qualities S31 have a seclusion estimation of $-3.45 \mathrm{~dB}$ and $\mathrm{S} 42$ have a segregation estimation of $-3.52 \mathrm{~dB}$. S21 and S31 have s parameter of disconnection above - $4 \mathrm{~dB}$ for Phenolic White Paper with er $=4.4[19][20]$. On the Figure. 11 demonstrates the Sparameter and disconnection estimations of each yield port 90-degree half breed coupler. 2.4 GHz 90-degree half and half coupler clear square Ring Patch with Ring Opening patch receiving wire utilizes two lines in and two lines out with 50-ohm impedance each line.

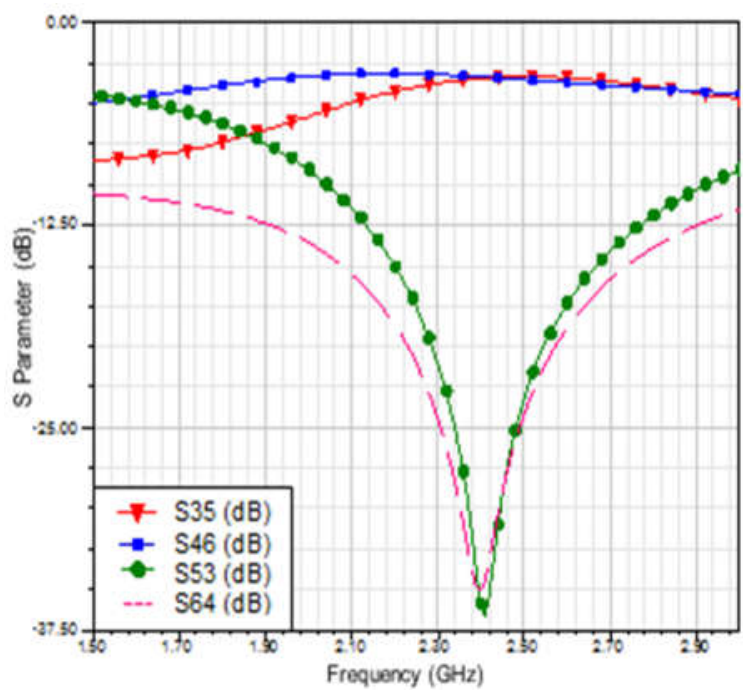

Figure 11. S parameter 90-degree hybrid coupler

The crossover directional coupler has a high level of evenness 90-degree half breed coupler, as any port can be utilized as the info and yield port. The yield ports will consistently be on the polar side of the abandoning the info port, and the segregated port will be the staying port on a similar side as the information port. The estimation of S parameter of each port at $2.4 \mathrm{GHz}$ recurrence activity can be pursued: S35 has esteem - $35.95 \mathrm{~dB}$, S46 has esteem - $35.09 \mathrm{~dB}$. S35 and S46 have s parameter blow $20 \mathrm{~dB}$ its great understanding[21]. S53 has esteem - 3.47 $\mathrm{dB}$ and S64 has esteem - $3.39 \mathrm{~dB}$. S35 and S64 have confinement above $-4 \mathrm{~dB}$ so that is a decent understanding.

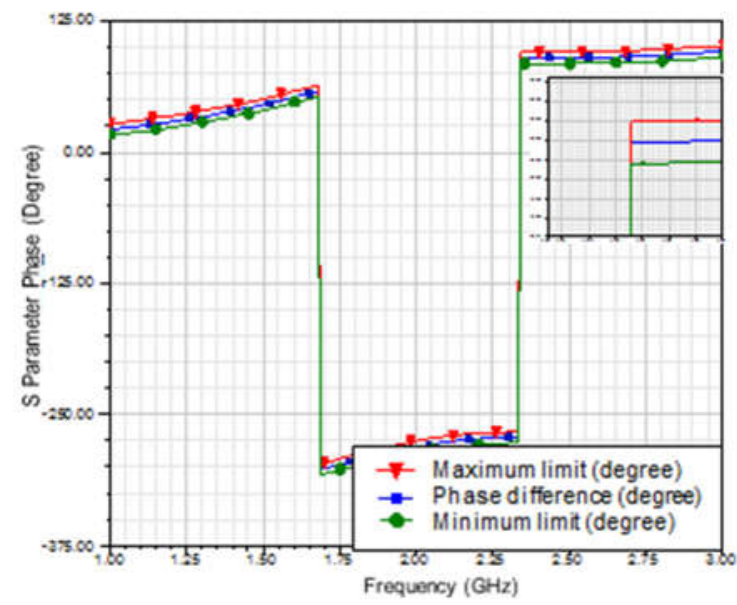

Figure 12. S parameter Phase difference output
Figure 12 demonstrates the stage distinction of the yield of each yield port. The stages are spoken to in various stage S parameters S35 and S46. S35 and S46 have contrasts in stage near 90 degree that is 89.54 degrees.

\section{CONCLUSION}

In this research, a minimized model reception apparatus for SIL radar, simple to create and ease material that has Phenolic White Paper material with $\varepsilon r=4.4$. This purposed usage has two radio wires and every reception apparatus has one resonators or transmission line $\lambda / 4$ with a similar working recurrence at every resonator that is 2.4 $\mathrm{GHz}$. This receiving wire is cluster model framework has directional radiation with high addition of $8.37 \mathrm{dBi}$ and straight polarization. the sustaining system comprises of six-port, two-port as a contribution from the receiving wire, and 4 port as yield: two yields as power divider with a similar power yield and two yields has 90 -degree stage contrast yield. The twofold control divider have S parameter S13 has an estimation of $-25.83 \mathrm{~dB}$ and S24 has an estimation of $-28.20 \mathrm{~dB}$ and the disengagement $\mathrm{S} 31$ has an estimation of $-3.45 \mathrm{~dB}$, and $\mathrm{S} 42$ has an estimation of $-3.52 \mathrm{~dB}$. The half and half directional Coupler has two contributions from the radio wire and two yields which produce an 89.54 degrees stage contrast and $\mathrm{S}$ yield parameters under $20 \mathrm{~dB}$ that is $\mathrm{S} 35$ has an estimation of $-35.95 \mathrm{~dB}$ and $\mathrm{S} 46$ has $-35.09 \mathrm{~dB}$. The, in general, have to size $3 \mathrm{mmx} 3 \mathrm{~mm}$ and all worth is a decent understanding

\section{REFERENCES}

[1] F. K. Wang, T. S. Horng, K. C. Peng, J. K. Jau, J. Y. Li, and C. C. Chen, "Single-antenna doppler radars using self and mutual injection locking for vital sign detection with random body movement cancellation," in IEEE Transactions on Microwave Theory and Techniques, 2011.

[2] E. M. Cheng et al., "Development of microstrip patch antenna sensing system for salinity and sugar detection in water," Int. J. Mech. Mechatronics Eng., 2014.

[3] G. W. M. Whyte, "Antennas for Wireless Sensor Network Applications by," Antenna, 2008.

[4] R. Yuwono, I. Mujahidin, A. Mustofa, and Aisah, "Rectifier using UFO microstrip antenna as electromagnetic energy harvester," Adv. Sci. Lett., 2015.

[5] H. Huang, "Flexible wireless antenna sensor: A review," IEEE Sensors Journal. 2013.

[6] P. B. Inder Bahl, Lumped Elements for RF and Microwave Circuits. 2013.

[7] X. Yi, C. Cho, J. Cooper, Y. Wang, M. M. Tentzeris, and R. T. Leon, "Passive wireless antenna sensor for strain and crack sensing - Electromagnetic modeling, simulation, and testing," Smart Mater. Struct., 2013.

[8] I. Mujahidin, S. H. Pramono, and A. Muslim, "5.5 Ghz Directional Antenna with 90 Degree Phase Difference Output," 2018.

[9] M. A. Afridi, "Microstrip Patch Antenna - Designing at $2.4 \mathrm{GHz}$ Frequency," Biol. Chem. Res., 2015.

[10] D. M. Pozar, "Microstrip antenna aperture-coupled to a microstripline," Electron. Lett., 2007.

[11] C. A. Balanis, Modern antenna handbook. 2007.

[12] J. Yamasaki, I. Ohta, T. Kawai, and Y. Kokubo, "Design of broadband semi-lumped and lumped element quadrature hybrids," in IEEE MTT-S International Microwave Symposium Digest, 2005.

[13] I. Mujahidin, "Directional $1900 \mathrm{MHz}$ Square Patch Ring Slot Microstrip Antenna For Wcdma," JEEMECS (Journal Electr. Eng. Mechatron. Comput. Sci., 2019.

[14] Y. J. Cheng, W. Hong, K. Wu, and Y. Fan, "A hybrid guidedwave structure of half mode substrate integrated waveguide and 
conductor-backed slotline and its application in directional couplers," IEEE Microw. Wirel. Components Lett., 2011.

[15] H. J. Visser and R. J. M. Vullers, "RF energy harvesting and transport for wireless sensor network applications: Principles and requirements," Proceedings of the IEEE. 2013.

[16] D. M. Pozar, "New results for minimum Q, maximum gain, and polarization properties of electrically small arbitrary antennas," in 3rd European Conference on Antennas and Propagation, 2009.

[17] Y. Yu, P. G. M. Baltus, A. De Graauw, E. Van Der Heijden, C. S. Vaucher, and A. H. M. Van Roermund, "A $60 \mathrm{GHz}$ phase shifter integrated with LNA and PA in $65 \mathrm{~nm}$ CMOS for phased array systems," in IEEE Journal of Solid-State Circuits, 2010.

[18] C. E. Balanis, "Antenna Theory: Analysis and Design, 3rd Edition - Constantine A. Balanis," Book. 2005.

[19] J. Lasmono, A. P. Sari, E. Kuncoro, and I. Mujahidin, "Optimasi Kerja Peluncur Roket Pada Robot Roda Rantai Untuk Menentukan Ketepatan Sudut Tembak," JASIEK (Jurnal Apl. Sains, Informasi, Elektron. dan Komputer), 2019.

[20] M. T. Prakarsa, D. Wahyuni, N. Rachman, and I. Mujahidin, "Optimasi Sistem Komunikasi Dari HT Dengan Hp Dalam Pelaksanaan Tugas Operasi Tni Ad Menggunakan Metode Dtmf," JASIEK (Jurnal Apl. Sains, Informasi, Elektron. dan Komputer), 2019.

[21] T. A. S, A. Rabi', D. Minggu, and I. Mujahidin, "Frequency Hopping Video Real Time Untuk Pengamanan Data Pengintaian Operasi Inteligence Tni," JASIEK (Jurnal Apl. Sains, Informasi, Elektron. dan Komputer), 2019. 